\title{
Design and Optimization of Hot-Filling Pasteurization Conditions: Cupuaçu (Theobroma grandiflorum) Fruit Pulp Case Study
}

\author{
Filipa V. M. Silva,* Rui C. Martins, and Cristina L. M. Silva \\ Escola Superior de Biotecnologia, Universidade Católica Portuguesa, Rua Dr. António Bernardino de Almeida, \\ 4200-072 Porto, Portugal
}

\begin{abstract}
Cupuaçu (Theobroma grandiflorum) is an Amazonian tropical fruit with a great economic potential. Pasteurization, by a hot-filling technique, was suggested for the preservation of this fruit pulp at room temperature. The process was implemented with local communities in Brazil. The process was modeled, and a computer program was written in Turbo Pascal. The relative importance among the pasteurization process variables (initial product temperature, heating rate, holding temperature and time, container vol ume and shape, cooling medium type and temperature) on the microbial target and quality was investigated, by performing simulations according to a screening factorial design. Afterward, simulations of the different processing conditions were carried out. The holding temperature $\left(T_{F}\right)$ and time ( $\left.t_{\text {hold }}\right)$ affected pasteurization value $(\mathrm{P})$, and the container volume $(\mathrm{V})$ influenced largely the quality parameters. The process was optimized for retail (1 L) and industrial (100 L) size containers, by maximizing volume average quality in terms of col or lightness and sensory "fresh notes" and minimizing volume average total color difference and sensory "cooked notes". Equivalent processes were designed and simulated $\left(\mathrm{P}_{91^{\circ} \mathrm{C}}=4.6 \mathrm{~min}\right.$ on Alicyclobacillus acidoterrestris spores) and final quality (color, flavor, and aroma attributes) was evaluated. Color was slightly affected by the pasteurization processes, and few differences were observed between the six equivalent treatments designed ( $T_{F}$ between 80 and $97^{\circ} \mathrm{C}$ ). $\mathrm{T}_{\mathrm{F}} \geq 91^{\circ} \mathrm{C}$ minimized "cooked notes" and maximized "fresh notes" of cupuaçu pulp aroma and flavor for $1 \mathrm{~L}$ container. Concerning the $100 \mathrm{~L}$ size, the "cooked notes" development can be minimized with $\mathrm{T}_{\mathrm{F}} \geq 91{ }^{\circ} \mathrm{C}$, but overall the quality was greatly degraded as a result of the long cooling times. A more efficient method to speed up the cooling phase was recommended, especially for the industrial size of containers.
\end{abstract}

\section{Introduction}

The design of a pasteurization process can be optimized in such a way that the main goal of safety is assured (achieve a certain microbial destruction, pasteurization value) and the quality changes are minimized. The optimization is possible because the thermal degradation kinetics of quality factors, such as color, flavor, texture or nutrients, is much less temperature-sensitive than the destruction of microorganisms (Teixeira et al., 1969; Lund, 1977; Holdsworth, 1985).

The following must be modeled to optimize a thermal process (Ávila and Silva, 1999): thermal kinetics of microbial target and relevant quality factors and process heat transfer into the product. Optimization can also be based on non-quality factors, such as productivity (Banga et al., 1993; Noronha, 1996) and energy consumption (Barreiro et al., 1984). In these cases, there is a compromise between these factors and those related with quality.

Several pasteurization conditions can achieve the same pasteurization value $(\mathrm{P})$, required for the preservation of a specific fruit product (purée, pulp, concentrate, juice, nectar, jam, etc.). However, only one or a few sets of thermal treatment conditions give maximum quality

\footnotetext{
* To whom correspondence should be addressed. E-mail: filipa@ esb.ucp.pt.
}

retention of the fruit product. The idea of minimizing quality losses during thermal processing of foods is not new, and several quality optimization studies are available in the literature in the field of sterilization of prepackaged foods (Holdsworth, 1985; Silva et al., 1994). There are a few food applied sterilization studies: white beans in brine (Van Loey et al., 1993), canned tuna (Banga et al., 1993), and again white beans (Ávila et al., 1999). However, regarding pasteurization of fruit products, no quality optimization study was found in the literature.

In this study, the pulp of an Amazonian fruit named cupuaçu (Theobroma grandiflorum) was used. On account of its exotic characteristics, pl easant aroma/flavor, and good transformation/conservation properties, cupuaçu has a great economic potential. Since cupuaçu pulp $\mathrm{pH}$ is approximately 3.4, a hot-filling pasteurization would enable its preservation at ambient conditions (Silva and Silva, 1997). This technique can be applied in the remote regions by the communities living in the production areas of the Amazon region, being inexpensive and appropriate for a varying supply of the fruit pulp (Silva, 2000). The pasteurization includes the following phases: (a) linear uniform heating phase until the hotfilling temperature; (b) uniform holding phase that maintains the hot-filling temperature during a specified time; (c) hot-filling into a container and sealing; and (d) 
nonuniform cooling phase. The process was implemented successfully with a local community in Brazil at a pilot scale level as follows (Silva, 2000): pulp was heated directly in a pan always stirring, so that the product has uniform temperature during the heating and holding stages of the pasteurization; the temperature was monitored continuously until the filling phase; $200-\mathrm{mL}$ glass flasks previously sterilized in boiling water were used; the nonuniform cooling phase was carried out by submerging the flasks in still water at room temperature $\left(\sim 30^{\circ} \mathrm{C}\right)$.

The main objectives of this research study were

(1) to model the process and develop a computer program for process simulation

(2) to determine the process variables that most affect the microbial target and the quality parameters

(3) to investigate differences between pasteurization value at the container surface $\left(P_{s}\right)$ and center $\left(P_{\text {center }}\right)$ and in terms of the container volume average $\left(P_{\text {ave }}\right.$ see eq 10)

(4) to design and simulate equivalent pasteurization processes

(5) to optimize pasteurization conditions for retail and industrial container sizes based on relevant quality factors of the fruit

\section{Process Modeling}

A mathematical model was developed to describe the pasteurization, by hot filling, of fruit products. Uniform heating and holding (at the hot-fill temperature) phases were assumed, and cooling by conduction followed the operation of container filling with the fruit product. On account of pulp high viscosity, only heat conduction was assumed within the pulp during the cooling phase. The heat transfer was model ed by a finite difference method. A computer program integrating food heat transfer properties, container characteristics, kinetics of microbial thermal inactivation, and quality changes, previously determined, was written. This program simulates the hot-filling pasteurization processes and is able to make predictions on quality and microbial (safety) parameters for different processing conditions at any processing time and container spot. Volume average results are also calculated at any processing time by integrating quality/ microbial parameters predictions at different container spots or finite volumes, dV (see eqs 10-12). Note, however, that only during the nonuniform cooling phase the results at different container spots (finite volumes) and in terms of volume average differ.

1. Heat Transfer During the Cooling Phase. The modeling of heat transfer during the cooling phase following the hot-filling operation was carried out by Silva and Silva (1997). A finite cylindrical geometry was assumed as well as constant thermophysical properties (food thermal conductivity, thermal diffusivity, and density). Heat transfer by conduction during the cooling by air or water was described by a finite differences method using non-capacitance surface nodes (Chau and Snyder, 1988; Chau and Gaffney, 1990; Silva, 1993; Welt et al., 1997). The overall surface heat transfer coefficient, $U$, included the resistances of the container wall, $x_{\text {cont }} / K_{\text {cont }}$, external radiation, $\mathrm{h}_{\mathrm{r}}$, and external natural convection, $\mathrm{h}_{\mathrm{c}}$ :

$$
\mathrm{U}=\frac{1}{\frac{1}{\mathrm{~h}_{\mathrm{c}}+\mathrm{h}_{\mathrm{r}}}+\frac{\mathrm{x}_{\text {cont }}}{\mathrm{K}_{\text {cont }}}}
$$

where $\mathrm{x}_{\text {cont }}$ and $\mathrm{K}_{\text {cont }}$ are the container thickness and thermal conductivity, respectively.

Empirical equations for prediction of natural convection surface heat transfer coefficients $\left(h_{c}\right)$ in vertical cylindrical walls were used (Holman, 1990). A computer program predicting time-temperature history during cool ing phase at any container point was written in Turbo Pascal (Silva and Silva, 1997). During the cooling process simulated $U$ decreased $\left(h_{c}\right.$ decreased, eq 1$)$ and was therefore recalculated along time. Silva and Silva (1997) validated experimentally the time-temperature profiles predicted by the model, during the water and air cooling of cupuaçu pulp canned in tin plate cans with $7.2 \mathrm{~cm}$ diameter and $3.5 \mathrm{~cm}$ height.

2. Kinetics of Thermally Induced Changes on Microbial Target and Cupuaçu Quality Factors. The kinetics of thermally induced changes on microbial target and relevant quality factors in cupuaçu pulp were determined in previous works from isothermal experiments (Silva and Silva, 1999; Silva et al., 1999; Silva et al., 2000a). Color changes were assessed with a tristimulus col orimeter and flavor/aroma changes were assessed with a sensory panel (Silva and Silva, 1999; Silva et al., 2000a).

2.1. Alicyclobacill us acidoterrestris Spores. Silva (2000) suggested and used for the first time the Alicyclobacillus acidoterrestris spores as reference (target) microorganism to design the pasteurization processes. The overall methodol ogy was presented for cupuaçu fruit pulp (Silva et al., 2000b). This bacterium has been detected in several spoiled commercial fruit juices that have been previously pasteurized. The A. acidoter restris spores (type strain, N CIMB 13137) thermal inactivation $\left(\mathrm{N} / \mathrm{N}_{\mathrm{o}}\right)$ in cupuaçu followed a first-order model, with a $\mathrm{D}_{91^{\circ} \mathrm{C}}$ value of $4.57 \mathrm{~min}$ and $\mathrm{a}$ z value of $8.9^{\circ} \mathrm{C}$ (Silva et al., 1999). Equation 2 presents the $\mathrm{N} / \mathrm{N}_{0}$ (reference temperature, $\mathrm{T}_{\text {ref }}=91^{\circ} \mathrm{C}$ ):

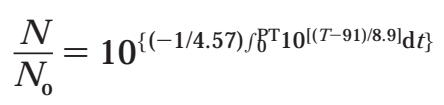

where $N / N_{0}$ is $A$. acidoterrestris spore reduction, $T$ is temperature $\left({ }^{\circ} \mathrm{C}\right), \mathrm{t}$ is time $(\mathrm{min})$, and $\mathrm{PT}$ is total processing time ( $\mathrm{min})$.

Microbial assessment of the process can also be based on the integrated lethality with respect to a constant temperature $\left(T_{\text {ref }}\right)$, known as pasteurization value $(P)$ :

$$
\mathrm{P}_{\mathrm{T}_{\text {ref }}}=\int_{0}^{\mathrm{PT}} 10^{\left[\left(\mathrm{T}-\mathrm{T}_{\text {ref }} / 8.9\right]\right.} \mathrm{dt}
$$

where $\mathrm{P}, \mathrm{PT}$, and $\mathrm{t}$ are expressed in minutes, and $\mathrm{T}$ and $\mathrm{T}_{\text {ref }}$ are in ${ }^{\circ} \mathrm{C}$.

2.2. Color of Cupuaçu Pulp. The kinetics of cupuaçu pulp color change in terms of CIE total color difference (TCD*) and lightness retention $\left(\mathrm{L}^{*} / \mathrm{L}_{\mathrm{o}}{ }^{*}\right)$ did not obey any of the mechanistic kinetic models and were better described with a power law (eqs 4 and 5, respectively) (Silva and Silva, 1999):

$$
\begin{aligned}
& \mathrm{TCD}^{*}=2.85 \mathrm{t}^{0.26 \mathrm{e}^{(-31000 / 8.314)[1 /(\mathrm{T}+273.15)-(1 / 373.15)]}} \\
& \frac{\mathrm{L}^{*}}{\mathrm{~L}_{\mathrm{o}}{ }^{*}}=1-0.044 \mathrm{t}^{0.20 \mathrm{e}^{(-36000 / 8.3144)[1 /(\mathrm{T}+273.15)-(1 / 373.15)]}}
\end{aligned}
$$

where $\mathrm{t}$ is time $(\mathrm{min})$ and $\mathrm{T}$ is temperature $\left({ }^{\circ} \mathrm{C}\right)$. 
2.3. Flavor and Aroma of Cupuaçu Pulp. Regarding sensory parameters, the following were evaluated on thermally treated cupuaçu: aroma "fresh notes" (FA), flavor "fresh notes" (FF), aroma "cooked notes" (CA), and flavor "cooked notes" (CF). These attributes were rated by a trained sensory panel on a 15 point scale, where 1 corresponds to the low and 15 to the high FA, FF, CA, and CF values of the scale. Aroma and flavor were rated using pasteurized pulp and a sweetened nectar $(25 \%$ pasteurized pulp, $15 \%$ sucrose and $60 \%$ water), respectively. With respect to flavor, the pulp was too acid to taste directly and a nectar had to be made. In the sensory sessions, the pasteurized cupuaçu samples were presented to the panel together with the two references coded with the letters $C$ and $F$. The reference $C$ was a sample heated for $20 \mathrm{~min}$ at $98^{\circ} \mathrm{C}$ and was agreed to be 4 for $F A$ and $F F$, and 15 for $C A$ and CF. The reference $F$ was freshly thawed, nonheated pulp, and was decided to be 15 for FA and FF, and 1 for CA and CF. Panelists were asked to smell and rate them for FA and CA. N ext, the same procedure was followed for the flavor, FF and $\mathrm{CF}$, by tasting the nectar. To model the thermal change kinetics of $F A, F F, C A$, and $C F$, isothermal (different time-temperature thermal treatments) experiments were carried out, and the treatment means of all the panelists and replicates were used. The kinetic parameters were determined by a one-step nonlinear regression ( $L$ und, 1983; Arabshahi and Lund, 1985; Van-Boekel, 1996). The kinetics of loss in "fresh notes" of aroma (FA) and flavor (FF) follow a first-order pattern, and "cooked notes" development was modeled with a first-order reversible kinetics (Villota and Hawkes, 1992) for aroma (CA) and flavor (CF) (Silva et al., 2000a). Kinetic models for FA, $F F, C A$, and $C F$ in cupuaçu are shown in eqs $6-9$, where time is expressed in min, temperatures in ${ }^{\circ} \mathrm{C}$, and $C \mathrm{~A}_{\infty}$ and $\mathrm{CF}_{\infty}$ refer to equilibrium $\mathrm{CA}$ and $\mathrm{CF}$, respectively:

$$
\begin{aligned}
& \frac{F A}{F A_{o}}=10^{\left\{-1 / 40.5 \int b^{\top} 10^{[(T-100) / 31.3]} d t\right\}} \\
& \frac{F F}{F F_{o}}=10^{\left\{-1 / 45.4 \int \mathrm{S}^{\mathrm{T}} 10^{[(\mathrm{T}-100) / 29.8]} \mathrm{dt}\right\}}
\end{aligned}
$$

$$
\begin{aligned}
\frac{C A}{C A_{o}} & =\frac{C A_{\infty}}{C A_{o}}+ \\
& \frac{C A_{o}-C A_{\infty}}{C A_{o}} e^{\left\{-0.09 \int b^{\top} e^{[(-79670 / 8.314)\{1 /(T+273.15)-(1 / 373.15)\}]} d t\right\}}
\end{aligned}
$$

$$
\begin{aligned}
& \frac{C F}{C F_{o}}=\frac{C F_{\infty}}{C F_{o}}+ \\
& \quad \frac{C F_{o}-C F_{\infty}}{C F_{o}} e^{\left.\left\{-0.115 / b^{\top} e^{[(-85190 / 8.314)\{(1 /(T+273.15)-(1 / 373.15)\}}\right] d t\right\}}
\end{aligned}
$$

Although "cooked notes" were linearly correlated with "fresh notes", the former was a better indicator for quality degradation (Silva et al., 2000a).

The comparison between $\mathrm{A}$. acidoterrestris spores, FA, and FF kinetic parameters can be made since thermal changes of all these factors followed a simple first-order kinetics. The $A$. acidoterrestris spores presented $D$ values much lower than those of $F A$ and $F F$. For instance $D_{91^{\circ} \mathrm{C}}$ was $4.6 \mathrm{~min}$ for $\mathrm{A}$. acidoterrestris, and 78.5 and $91 \mathrm{~min}$ for FA and FF, respectively (Silva, 2000). Moreover, the $A$. acidoterrestris $D$ value was greatly affected by the temperature $\left(z=9^{\circ} \mathrm{C}\right)$ in comparison with FA ( $z=31$ $\left.{ }^{\circ} \mathrm{C}\right)$ or FF $\left(\mathrm{z}=30{ }^{\circ} \mathrm{C}\right)($ Silva, 2000). In other words, the inactivation of $\mathrm{A}$. acidoterrestris at higher temperatures provokes less quality degradation. Therefore, there is the opportunity of process optimization based on maximization of FA and FF retention.

3. Computer Program Development. A computer program was written in Turbo Pascal language. The program simulates the pasteurization processes, calculating the pasteurization value $(P)$, microbial retention $\left(\mathrm{N} / \mathrm{N}_{\mathrm{o}}\right)$, and all of the quality factors (absolute values, $\mathrm{F}$, or in some cases as retention, $F / F_{0}$ ) in a finite cylinder for a heat-hold-cool thermal process. Note that the holding phase may not be required, depending on the filling temperature and container volume.

The quality and microbial results from the process simulations were computed along process time and expressed at any container point (eqs 2-9) such as center or surface, and in terms of volume average:

$$
\begin{gathered}
\mathrm{P}_{\text {ave }}=\frac{1}{\mathrm{~V}_{\mathrm{T}}} \int_{0}^{\mathrm{V}_{\mathrm{T}} \mathrm{P} \mathrm{dV}} \\
\mathrm{TCD}_{\mathrm{ave}}^{*}=\frac{1}{\mathrm{~V}_{\mathrm{T}}} \int_{0}^{\mathrm{V}_{\mathrm{T}}} \mathrm{TCD}^{*} \mathrm{dV} \\
\left(\frac{\mathrm{F}}{\mathrm{F}_{\mathrm{o}}}\right)_{\text {ave }}=\frac{1}{\mathrm{~V}_{\mathrm{T}}} \int_{0}^{\mathrm{V}_{\mathrm{T}}} \frac{\mathrm{F}}{\mathrm{F}_{\mathrm{o}}} \mathrm{dV}
\end{gathered}
$$

where ave refers to average, $\mathrm{V}_{\mathrm{T}}$ is the total volume, and $\mathrm{F} / \mathrm{F}_{\mathrm{o}}$ is the microbial/quality factor retention.

Again, only during the nonuniform cooling phase do the results at different container points differ, as a result of the conduction mechanism. The process simulation will finish when the temperature in the container center is $\leq 40{ }^{\circ} \mathrm{C}$ during the cooling phase. A schematic flow sheet of the computer program developed is presented in Figure 1.

\section{Design and Optimization Procedure}

Norback (1980) defined the five elements common to all optimization problems: (1) the identification of the process design variables that can be controlled, (2) the requirements that must be met (constraints or restrictions), (3) the definition of the objective function to be optimized, (4) the mathematical model that simulates the process, and (5) an optimization technique. In the case of the optimization of cupuaçu pulp pasteurization, using a hot-filling method, the design variables are listed in Table 1. The microbial requirement is a specific reduction on the spore population of A. acidoterrestris bacteria, depending on the fruit product. The objective functions are the maximization of $F A / F A_{0}, F F / F F_{0}, L * / L_{0} *$, and the minimization of $\mathrm{CA} / \mathrm{CA}_{0}, \mathrm{CF} / \mathrm{CF}_{0}$, and TCD*. In the previous section the process was modeled and a computer program for process simulation was developed. Finally, the optimization technique was carried out by analyzing the results of equivalent pasteurization treatments (plots of results vs treatment temperature) and searching for maximum ( $\left.F A, F F, L * / L_{0}^{*}\right)$, or minimum (TCD*, CA, CF ), depending on the factor evaluated.

1. Cupuaçu Pulp and Container Thermal Properties. The cupuaçu pulp thermal properties were necessary to simulate any pasteurization process for this fruit. Density $(\rho)$, experimentally determined with a picnometer, was found to be $1031 \pm 0.003 \mathrm{~kg} / \mathrm{m}^{3}$; the thermal conductivity $\left(\mathrm{K}_{\mathrm{fp}}\right)$, calculated using empirical equations (Sweat, 1986), was $0.539 \mathrm{~W} /\left(\mathrm{m} \cdot{ }^{\circ} \mathrm{C}\right)$; and thermal diffusivity $(\alpha)$, determined experimentally using the Dickerson 


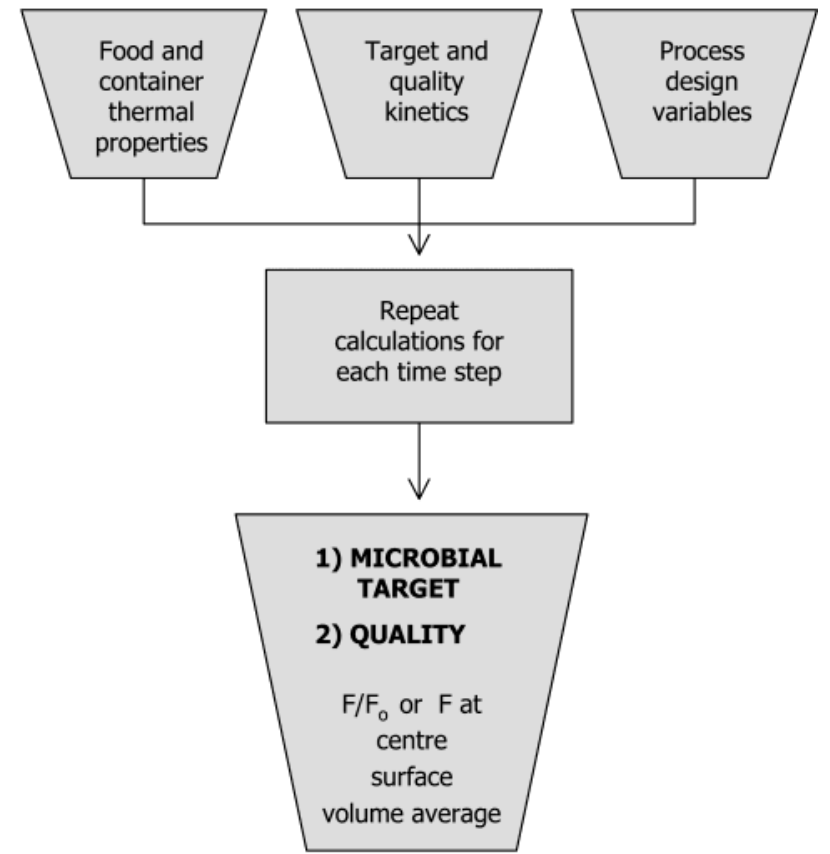

Figure 1. Schematic flow sheet of the computer program.

Table 1. Pasteurization Design Variables

\begin{tabular}{|c|c|c|c|}
\hline $\begin{array}{l}\text { pasteurization } \\
\text { phase }\end{array}$ & $\begin{array}{l}\text { variable } \\
\text { symbol }\end{array}$ & variable denomination & $\begin{array}{c}\text { variable } \\
\text { units }\end{array}$ \\
\hline \multirow{3}{*}{$\begin{array}{l}\text { heating } \\
\text { holding }\end{array}$} & $\mathrm{H}_{\text {rate }}$ & $\begin{array}{l}\text { heating rate } \\
\text { initial temperature }\end{array}$ & ${ }^{\circ} \mathrm{C} / \mathrm{min}$ \\
\hline & $\mathrm{T}_{\mathrm{F}}$ & holding/filling temperature & \\
\hline & $t_{\text {hold }}$ & holding time & mir \\
\hline \multirow[t]{3}{*}{ cooling } & $\mathrm{V}$ & container volume & $\mathrm{L}$ \\
\hline & S & $\begin{array}{l}\text { container shape } \\
\text { (half-height/radius) }\end{array}$ & \\
\hline & $\begin{array}{l}\mathrm{T}_{\text {cool }} \\
\mathrm{CM}\end{array}$ & $\begin{array}{l}\text { cooling medium temperature } \\
\text { cooling medium (air/water) }\end{array}$ & ${ }^{\circ} \mathrm{C}$ \\
\hline
\end{tabular}

(1965) method, was $(1.671 \pm 0.124) \times 10^{-7} \mathrm{~m}^{2} / \mathrm{s}$. The heat capacity can be calculated $\left(\mathrm{C}_{\mathrm{p}}=\mathrm{K}_{\mathrm{fp}} / \rho \cdot \alpha\right)$, 3128.6 $\mathrm{J} /(\mathrm{kg} \cdot \mathrm{K})$.

All of the simulations were performed for cylindrical containers, using tin plate thermal properties $\left(x_{\text {cont }}=\right.$ $0.00022 \mathrm{~m} ; \mathrm{K}_{\text {cont }}=60 \mathrm{~W} /(\mathrm{m} \cdot \mathrm{K})$; thermal emissivity, $\epsilon_{\text {cont }}$ $=0.07)$. There is an error associated to this, since the thickness of the container varies $(0.22-3 \mathrm{~mm})$ with its capacity, especially in the range simulated (0.1-200 L). For large container volumes ( $\gg 1 \mathrm{~L})$, the top and base walls of the container are thicker than the sidewall. However, the $U$ was not affected significantly by the container thickness $\left(x_{\text {cont }}\right)$, because $K_{\text {cont }}$ is very high in metals and the resistance offered to the heat transfer is very low. The fill headspace is another factor that affects the heat transfer properties of the container, but it was not considered in this study.

2. Screening Process Variables Effects on Microbial and Quality Parameters. To understand better the relative importance of process variables, a factorial study with a screening design was carried out before setting up the design and optimization methodology.

The pasteurization variables are listed in Table 1, and the process design depends on the variables values associated with each pasteurization phase. Those variables can be controlled and their effect on quality and microbial inactivation can be predicted. The $T_{0}$ (product initial temperature), $T_{F}$ (filling/hol ding temperature), $t_{\text {hold }}$ (holding time), CM (cooling medium), and $\mathrm{T}_{\text {cool }}$ (CM temperature) are the easiest variables to control, because as opposed to variables such $\mathrm{V}$ (container volume) and S (container shape, $\mathrm{S}=$ half-height/radius), they are not specified by the client. The $\mathrm{H}_{\text {rate }}$ is more difficult to control, depending on the heat transfer characteristics of the product and the heating system.

An eighth fraction ( $2^{8-3}$ Resolution IV, 8 variables, $2^{5}$ $=32$ experiments without center points) screening factorial design with 4 center points, giving a total of 36 simulations, was carried out to determine the most important variables to obtain the required pasteurization value $(P)$. Quality factors were also monitored. Differences between center, surface, and volume average $P$ were investigated. The variables ranges selected were: $5<\mathrm{T}_{\mathrm{o}}\left({ }^{\circ} \mathrm{C}\right)<30,4<\mathrm{H}_{\text {rate }}\left({ }^{\circ} \mathrm{C} / \mathrm{min}\right)<50,70<\mathrm{T}_{\mathrm{F}}\left({ }^{\circ} \mathrm{C}\right)<$ 97, $0<\mathrm{t}_{\text {hold }}(\mathrm{min})<30,0.1<\mathrm{V}(\mathrm{L})<200,1.1<\mathrm{S}<2$, $5<\mathrm{T}_{\text {cool }}\left({ }^{\circ} \mathrm{C}\right)<30$, air vs water cooling. The range of values studied was representative of most practical situations. The input variables with most negative effects on the quality parameters were also investigated with this screening design. The statistical software Statgraphics (Version 5) was used for analysis. The water vs aircooling variable corresponds to different $U$ values.

3. Design and Optimization Methodology. A. acidoterrestris spores were the mi crobial target used (Silva et al., 1999). The methodology suggested by Silva et al. (2000b) to establish the necessary reduction on A. acidoter restris spores was followed. Regarding cupuaçu pulp/ purée, a one decimal reduction on $A$. acidoterrestris spores $\left(\mathrm{N} / \mathrm{N}_{\mathrm{o}}=0.1\right.$ or $\left.\mathrm{P}_{91^{\circ} \mathrm{C}}=4.6 \mathrm{~min}\right)$ ensures a safe process and was defined after performing growth, heat resistance, and storage/shelf life studies with this fruit (Silva et al., 2000b). Based on the results of the screening factorial study mentioned in the previous point of this section, equivalent pasteurization conditions $\left(\mathrm{N} / \mathrm{N}_{\mathrm{o}}=0.10\right.$ at the process coldest point, the surface) were designed and the process was optimized by minimizing the color and sensory changes. Cupuaçu pulp quality attributes were assessed in terms of volume average. As described previously, the "fresh notes" (FA, FF) were rated on a scale of 4 (severely heated sample) to 15 (nonheated sample) whereas a scale of 1 (nonpasteurized cupuaçu) to 15 (very severe heat treatment) was used with the "cooked notes" (CA, CF ) (Silva et al., 2000a). Optimization was carried out for two different container sizes: $1 \mathrm{~L}$, simulating retail size, and $100 \mathrm{~L}$, simulating industrial size. The results of this optimization study were only valid for the hot-filling pasteurization process proposed.

\section{Results and Discussion}

1. Process Variables Effect on Microbial and Quality Factors. Results of the screening factorial study are presented in Table 2. The $T_{F}$ and thold were the variables responsible ( $p<0.05)$ for reaching the pasteurization target at container surface, $\mathrm{P}_{s}$. From the statistical analysis (Statgraphics, Version 5), the $T_{0}, S$, and $T_{\text {cool }}$ did not have significant effects on $P$ and quality factors $(p>0.05)$ within the ranges studied. The $\mathrm{H}_{\text {rate }}$ was significant just for the color quality parameters, TCD* and L*. In general, the quality could be improved with smaller container volumes, low $\mathrm{T}_{\mathrm{F}}$ and $\mathrm{t}_{\text {hold, }}$ high $\mathrm{H}_{\text {rate }}$ and using water for the product cooling.

1.1. Center, Surface and Vol ume AverageP. Among the eight variables investigated, the $P_{\text {ave }}$ (volume average $P)$ and $P_{\text {center }}(P$ at container center) were significantly $(p<0.05)$ affected by the $T_{F}$ and $V$, whereas the $P_{S}(P$ at container surface, coldest point of the process) was affected by the $T_{F}$ and $t_{\text {hold. }}$. The higher are $T_{F}$ and $t_{\text {hold }}$, the higher is $\mathrm{P}_{\mathrm{s}}$. All other process variables did not have 
Table 2. Influence of Design Variables on Pasteurization Value (P) and Average Quality Factors ${ }^{\mathbf{a}}$

\begin{tabular}{|c|c|c|c|c|c|c|c|c|c|}
\hline \multirow[b]{2}{*}{ design variable } & \multicolumn{9}{|c|}{ response } \\
\hline & $P_{\text {center }}$ & $P_{\text {ave }}$ & $P_{s}$ & TCD* & $L^{*} / L_{0} *$ & $\mathrm{FA} / \mathrm{FA} \mathrm{A}_{\circ}$ & $F F / F F_{0}$ & $\mathrm{CA} / \mathrm{CA}_{\circ}$ & $\mathrm{CF} / \mathrm{CF}_{\mathrm{o}}$ \\
\hline $\mathrm{T}_{\mathrm{o}}$ & - & - & - & - & - & - & - & - & - \\
\hline $\mathrm{H}_{\text {rate }}$ & - & - & - & + & + & - & - & - & - \\
\hline$T_{F}$ & + & + & + & + & + & + & + & - & - \\
\hline$t_{\text {hold }}$ & - & - & + & - & - & + & + & - & - \\
\hline V & + & + & - & + & + & + & + & + & - \\
\hline S & - & - & - & - & - & - & - & - & - \\
\hline$T_{\text {cool }}$ & - & - & - & - & - & - & - & - & - \\
\hline CM & - & - & - & + & + & + & + & - & - \\
\hline
\end{tabular}

${ }^{a}(+)$ variable with significant effect $(p<0.05)$; $(-)$ variable effect not significant $(p>0.05)$.

Table 3. Volume Average Quality Results Obtained for Equivalent Pasteurization Processes $\left(T_{F}-t_{\text {hold }}\right)$

\begin{tabular}{|c|c|c|c|c|c|c|c|c|c|c|c|c|c|}
\hline \multirow[b]{2}{*}{ factor } & \multirow{2}{*}{$\begin{array}{c}\text { fresh } \\
\text { nonheated }\end{array}$} & \multicolumn{2}{|c|}{$80^{\circ} \mathrm{C}-80 \mathrm{~min}$} & \multicolumn{2}{|c|}{$85^{\circ} \mathrm{C}-21 \mathrm{~min}$} & \multicolumn{2}{|c|}{$91^{\circ} \mathrm{C}-3.5 \mathrm{~min}$} & \multicolumn{2}{|c|}{$93^{\circ} \mathrm{C}-1.7 \mathrm{~min}$} & \multicolumn{2}{|c|}{$95^{\circ} \mathrm{C}-0.58 \mathrm{~min}$} & \multicolumn{2}{|c|}{$97^{\circ} \mathrm{C}-0 \mathrm{~min}$} \\
\hline & & $1 \mathrm{~L}$ & $\overline{100 \mathrm{~L}}$ & $1 \mathrm{~L}$ & $100 \mathrm{~L}$ & $1 \mathrm{~L}$ & $100 \mathrm{~L}$ & $1 \mathrm{~L}$ & $100 \mathrm{~L}$ & $1 \mathrm{~L}$ & $100 \mathrm{~L}$ & $\overline{1 L}$ & $100 \mathrm{~L}$ \\
\hline TCD* & 0 & 4.7 & 5.5 & 4.3 & 5.6 & 4 & 6 & 4 & 6.2 & 4 & 6.5 & 4.1 & 6.7 \\
\hline $\mathrm{L}^{*} / \mathrm{L}_{0} *$ & 1 & 0.94 & 0.93 & 0.94 & 0.93 & 0.95 & 0.93 & 0.95 & 0.93 & 0.94 & 0.92 & 0.94 & 0.92 \\
\hline FA & 15 & 4.2 & 1.3 & 7.5 & 1.9 & 9.1 & 2 & 9.2 & 1.9 & 9.1 & 1.8 & 8.9 & 1.7 \\
\hline FF & 15 & 5 & 1.8 & 8 & 2.5 & 9.4 & 2.5 & 9.4 & 2.4 & 9.3 & 2.3 & 9.1 & 2.1 \\
\hline CA & 1 & 13.2 & 14.7 & 10 & 14 & 7.9 & 12.8 & 7.8 & 12.3 & 7.9 & 11.8 & 8.1 & 11.6 \\
\hline CF & 1 & 11.7 & 12.5 & 9.4 & 11.8 & 7.7 & 10.2 & 7.6 & 10.1 & 7.6 & 9.7 & 7.8 & 8.9 \\
\hline
\end{tabular}

a significant effect on $\mathrm{P}$ (center, surface, and volume average), within the variable ranges investigated. When the container volume increases (V), the differences in $\mathrm{P}$ achieved at the center and surface, the coldest point of the process, increases as well. As expected, the pasteurization value obtained at the container surface, $\mathrm{P}_{\mathrm{s}}$, was always the lower value at the end of the pasteurization process. The surface was the container spot selected to achieve the minimum process time equivalent to $4.6 \mathrm{~min}$ at $91^{\circ} \mathrm{C}\left(\mathrm{P}_{\mathrm{s}, 91^{\circ} \mathrm{C}}=4.6 \mathrm{~min}\right)$. In this way all of the container spots will have at least this $P$ and a safe process will be assured.

1.2. Volume Average Quality Factors. F or quality, although the quality changes were less at the surface and differences between the center and surface exist, especially for large volumes, the vol ume average was used to assess all factors. The TCD* and $L * / L_{0} *$ were significantly affected, by decreasing order of importance, by $T_{F}, V, C M$ and $H_{\text {rate. }}$ The $V, T_{F}$, thold, and $C M$ caused significant changes on FA and FF sensory attributes. The CA was only affected by $\mathrm{V}$, whereas no variable affected $\mathrm{CF}$.

2. Optimization. The input variables of minor importance for the $\mathrm{P}$ were fixed at constant values $\left(\mathrm{T}_{0}=20\right.$ ${ }^{\circ} \mathrm{C}, \mathrm{H}_{\text {rate }}=4{ }^{\circ} \mathrm{C} / \mathrm{min}, \mathrm{S}=1, \mathrm{~T}_{\text {cool }}=20^{\circ} \mathrm{C}, \mathrm{CM}=$ water). Then, the following equivalent processes were designed $\left(T_{F}, t_{\text {hold }}\right): 80^{\circ} \mathrm{C}-80 \mathrm{~min}, 85^{\circ} \mathrm{C}-21 \mathrm{~min}, 91{ }^{\circ} \mathrm{C}-3.5 \mathrm{~min}$, $93^{\circ} \mathrm{C}-1.7 \mathrm{~min}, 95^{\circ} \mathrm{C}-0.58 \mathrm{~min}, 97^{\circ} \mathrm{C}-0 \mathrm{~min}$. Although the listed processes have different time and temperature conditions, they are equivalent, because they all have the same degree of inactivation on the $A$. acidoterrestris spores.

The optimization was based on the effects of different $\left(T_{F}-t_{\text {hold }}\right)$ pasteurizations on quality. Volume average results are presented in Table 3 and Figures 2-4.

2.1. Color. The color was not greatly affected by the pasteurization conditions applied. The same conclusion was taken from the simulations of five different hot-filling pasteurizations (filling temperatures between 70 and 87 $\left.{ }^{\circ} \mathrm{C}\right)$ carried out in Brazil (Silva, 2000). Regarding final total color differences from the fresh nonheated cupuaçu pulp, TCD* values obtained for different $\mathrm{T}_{\mathrm{F}}-\mathrm{t}_{\text {hold }}$ treatments are difficult to detect by the human eye, and optimization was unnecessary: TCD* ranged between 4 and 4.7 , and 5.5 and 6.7 for 1 and $100 \mathrm{~L}$, respectively (Figure 2). In fact, the TCD* results (TCD* $<7$ ) were expected, because according to the isothermal kinetic experiments carried out previously (Silva and Silva, 1999), temperatures of 80,90 , and $100{ }^{\circ} \mathrm{C}$ required approximately 90,40 , and 20 min, respectively, to obtain TCD* $>6$. The same conclusions apply to the color lightness retention $\left(L^{*} / L_{0} *\right)$, with values between 0.92 and 0.95 , for 1 and $100 \mathrm{~L}$, respectively (Figure 2). Overall, the color obtained was very similar for all of the processes, and optimization was made difficult and not worthy.

2.2. Aroma and Flavor. As opposed to color, the pasteurization of the pulp caused great changes in the aroma and flavor of the pulp. Some "fresh notes" (FA, FF) were lost and other "cooked notes" (CA, CF ) were developed. The $100 \mathrm{~L}$ container greatly affected the FA and FF by decreasing at any hot-filling temperature the value from 15 to approximately 2 . This score is far beyond the minimum of 4 established previously by a sensory panel for a severely pasteurized sample, which is equivalent to a sample heated for $20 \mathrm{~min}$ at $98^{\circ} \mathrm{C}$ (Silva et al., 2000a). No optimization should be attempted, since regardless the $T_{F}-t_{\text {hold }}$ applied the result was approximately the same $(\approx 2)$ due to the container large size. A method to decrease the cooling phase time is recommended. In fact, for containers with these dimensions (100 L ), aseptic filling rather than hot-filling pasteurization is recommended. Regarding the $1 \mathrm{~L}$ container size, the temperatures of 80 and $85^{\circ} \mathrm{C}$ resulted in lower values of "fresh notes" (F A, FF). The long holding times required for the achievement of the target $P$, respectivel $y, 80$ and $21 \mathrm{~min}$, were responsible for this negative result. FA increased with increasing pasteurization temperature, reaching 8.9-9.2 for temperatures above or equal to 91 ${ }^{\circ} \mathrm{C}$ (Figure 3). Maximum FF were slightly higher than FA, ranging between 9.1 and 9.4 for the same temperature range (Figure 3 ). The flavor characteristics do not change as much as the aroma characteristics. This was expected, since the aroma was assessed in the pasteurized pulp, whereas the flavor was measured in a diluted nectar with $25 \%$ of pulp (Silva et al., 2000a).

CA and CF were always lower for the $1 \mathrm{~L}(\sim 8-13)$ container compared with the $100 \mathrm{~L}$ container size ( 915), and the values decreased with increasing hot-filling temperature, especially until $91{ }^{\circ} \mathrm{C}$ (Figure 4). The "cooked notes" formation was minimized with higher temperatures $\left(\geq 91{ }^{\circ} \mathrm{C}\right)$, being around 8 for $1 \mathrm{~L}$ and ranging between 10 and 12 for $100 \mathrm{~L}$ (Table 3, Figure 4). 
(a)

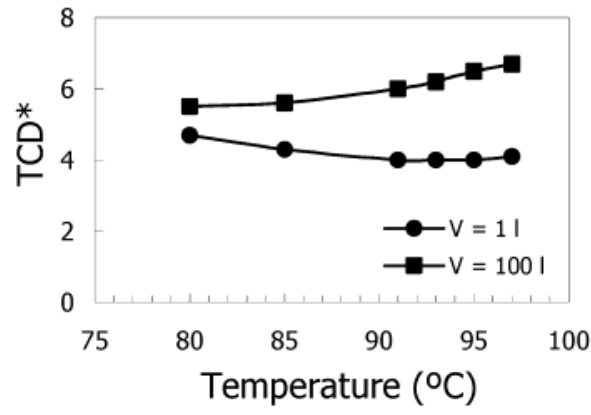

(b)

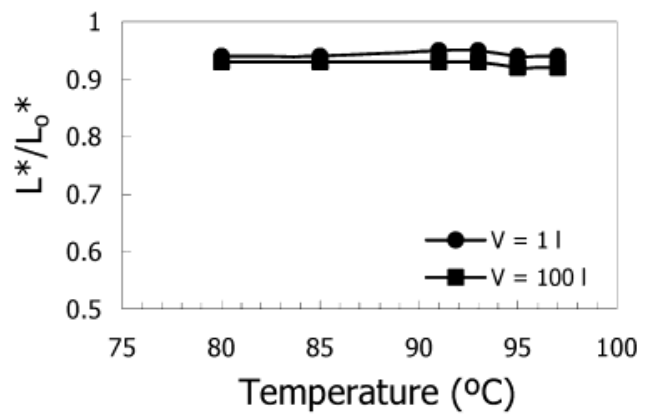

Figure 2. Optimization of hot-filling pasteurization conditions for color: (a) $T C D^{*}$ and (b) $L^{*} / L_{0}^{*}$.

(a)

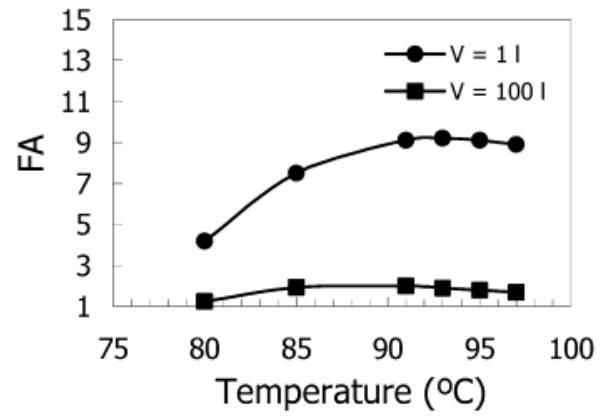

(b)

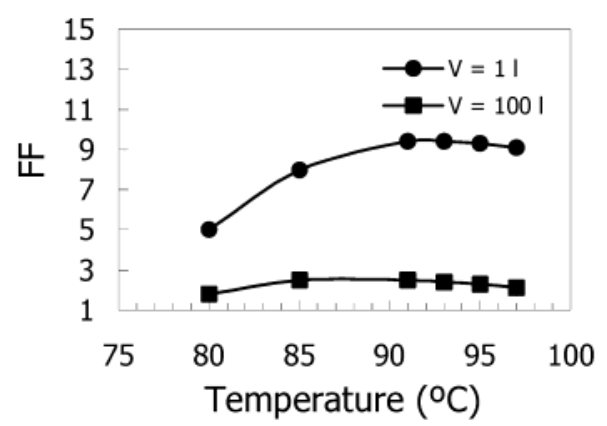

Figure 3. Optimization of hot-filling pasteurization conditions for "fresh notes": (a) aroma (FA) and (b) flavor (FF).

(a)

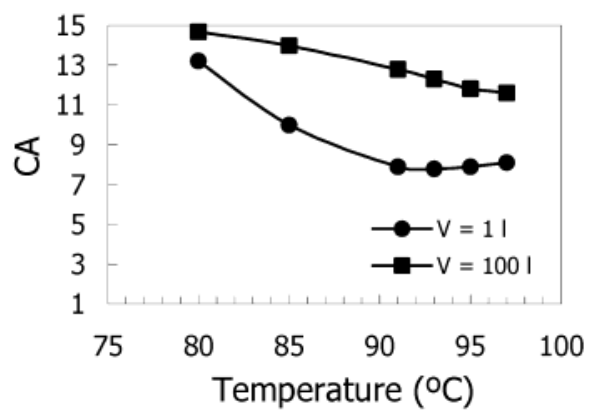

(b)

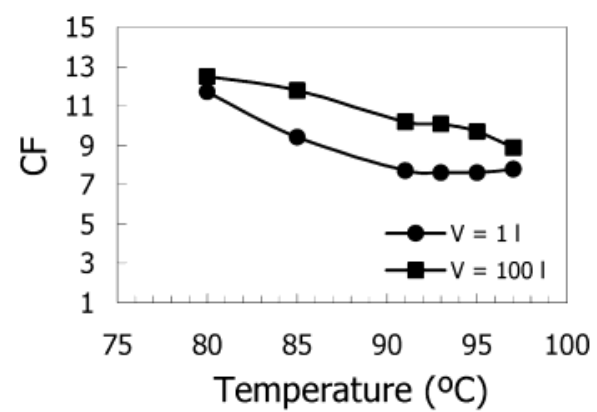

Figure 4. Optimization of hot-filling pasteurization conditions for "cooked notes": (a) aroma (CA) and (b) flavor (CF).

In the same way that $\mathrm{FA}<\mathrm{FF}$, the $\mathrm{CA}$ was higher than $\mathrm{CF}$. Higher temperatures $\left(\geq 91^{\circ} \mathrm{C}\right)$ maximize the $\mathrm{CA}$ and $\mathrm{CF}$ attributes for both container sizes.

\section{Conclusions and Recommendations for Further Work}

$F A, F F, C A$, and $C F$ quality factors changed by a great extent with all of the pasteurization treatments (equivalent pasteurizations) applied to cupuaçu pulp, but in contrast, the color was slightly affected, color changes being difficult to perceive visually (TCD* $<7)$. CA was the factor that most changed with the pasteurization and should be used in further studies. Optimization was carried out on the basis of sensory attributes and $T_{F} \geq$ $91{ }^{\circ} \mathrm{C}$ (corresponding to lower $t_{\text {hold }}$ ) was recommended for the retail size containers. In the case of industrial size containers, the sensory properties of original cupuaçu pulp $(F A=F F=15, C A=C F=1)$ were severely affected $(F A=2, F F=2.5, C A=12, C F=10)$. Therefore, alternative methods to speed up the cooling phase of the pulp such as aseptic processing, spin cooling, or colder cooling water are recommended. This would have also a great increase of productivity. In resume, the importance of using sensory properties to assess quality of thermally processed foods was reinforced with this work.

Concerning further work, modeling of other kinds of pasteurization processes (e.g., nonuniform heating phase) that may occur in real pasteurization of food products should be attempted. Partial contributions of heating, holding, and cooling phases of the pasteurization for "fresh notes" and "cooked notes" changes should be investigated in more detail. Finally, computer predictions of quality and microbial changes at optimal conditions should be experimentally validated.

The overall methodology developed in this work, for hot-filling pasteurization of cupuaçu pulp, including process design based on A. acidoter restris spore reduction, determination of relevant quality factors thermal change kinetics, and process modeling and optimization, can be applied to other food products if thermal properties are also determined in those products. 


\section{Notation}

$\mathrm{C}_{\mathrm{p}} \quad$ fruit pulp heat capacity $(\mathrm{J} /(\mathrm{kg} \cdot \mathrm{K}))$

D D value: time required to reduce the parameter by a factor of $10(\mathrm{~min})$

$\mathrm{F} \quad$ microorganism/quality factor

$\mathrm{F} / \mathrm{F}_{0} \quad$ factor retention

h surface heat transfer coefficient $\left(W /\left(m^{2} \cdot K\right)\right)$

K thermal conductivity $(\mathrm{W} /(\mathrm{m} \cdot \mathrm{K}))$

I container half-height $(\mathrm{m})$

L color lightness

$\mathrm{N} \quad$ number of viable spore cells remaining

P pasteurization value: integrated lethality in a container point (min)

PT total process time ( $\mathrm{min}$ )

$r \quad$ container radius $(\mathrm{m})$

S container shape; half-height $/$ radius $=1 / r$ (dimensionless)

t time (min)

$\mathrm{T}$ temperature at a single point of the container $\left({ }^{\circ} \mathrm{C}\right)$

$\mathrm{U} \quad$ overall surface heat transfer coefficient $\left(\mathrm{W} /\left(\mathrm{m}^{2}\right.\right.$. $\mathrm{K}))$

$\checkmark \quad$ container volume $(L)$

$x \quad$ thickness $(m)$

z $\quad z$ value: number of ${ }^{\circ} \mathrm{C}$ required to reduce the $\mathrm{D}$ value by a factor of $10\left({ }^{\circ} \mathrm{C}\right)$

Greek symbols

$\alpha \quad$ fruit pulp/puree thermal diffusivity $\left(\mathrm{m}^{2} / \mathrm{s}\right)$

$\epsilon \quad$ emissivity of the container (dimensionless)

$\rho \quad$ fruit pulp/puree density $\left(\mathrm{kg} / \mathrm{m}^{3}\right)$

\section{Subscripts}

o refers to initial time, time zero, nonheated cupuaçu sample

ave refers to the average volume

c natural convection

center refers to container center

cont refers to container

cool refers to cooling media

$\mathrm{F} \quad$ refers to hot-filling conditions of pasteurization

$\mathrm{fp} \quad$ refers to fruit pulp

hold refers to holding phase of pasteurization

$r$ radiative convection

ref reference

$\mathrm{s} \quad$ refers to the container surface

$T \quad$ refers to total

$\infty$ refers to infinite time or time to reach the equilibrium

Superscripts

* $\quad$ refers to CIE color space coordinates

Abbreviations

CA "cooked notes" of aroma

CF "cooked notes" of flavor

CM cooling medium (air/water)

FA "fresh notes" of aroma

FF "fresh notes" of flavor

$\mathrm{H}_{\text {rate }} \quad$ uniform heating rate phase of pasteurization $\left({ }^{\circ} \mathrm{C} /\right.$ $\min$ )

TCD total color difference

\section{Acknowledgment}

Part of this work was presented at the 8th International Congress on Engineering and Food, Puebla, Mexico,
April 9-13, 2000. The author F.V.M.S. acknowledges Praxis XXI Ph.D. grant BD-3163-94 to Fundação para a Ciência e a Tecnologia, Ministério da Ciência e a Tecnologia, Portugal. The authors thank European Union, project "Etude Pluridisciplinaire de Transformations de Fruits Amazoniens en Vue de Leur Valorisation Commerciale par les Organisations Paysannes Existantes", contract STD n. ERB-TS3-CT94-0300.

\section{References and Notes}

Arabshahi, A.; Lund, D. B. Considerations in calculating kinetic parameters from experimental data. J. Food Process Eng. 1985, 7(4), 239-251.

Ávila, I. L. M. B.; Silva, C. L. M. Methodologies to optimize thermal processing conditions: an overview. In Processing Foods, Quality Optimization and Process Assessment; Oliveira, F. A. R., Oliveira, J . C., Eds.; CRC: New York, 1999; pp 67-82.

Ávila, I. L. M. B.; Smout, C.; Silva, C. L. M.; Hendrickx, M. Development of a novel methodology to validate optimal sterilization conditions for maximizing the texture quality of white beans in glass jars. Bi otechnol. Prog. 1999, 15(3), 565572.

Banga, J . R.; Alonso, A. A.; Gallardo, J . M.; Perez-Martin, R. I. Computer aided design and optimisation of sterilisation of canned tuna. Paper presented at the 6th International Congress on Engineering and Food, Chiba, J apan, May 2327, 1993.

Barreiro, J . A.; Perez, C. R.; Guariguata, C. Optimisation of energy consumption during the heat processing of canned foods. J . Food Eng. 1984, 3(1), 27-37.

Chau, K. V.; Snyder, G. V. Mathematical model for temperature distribution of thermally processed shrimp. Trans. ASAE 1988, 31(2), 608-612.

Chau, K. V.; Gaffney, J . J . A finite-difference model for heat and mass transfer in products with internal heat generation and transpiration. J . Food Sci. 1990, 55(2), 484-487.

Dickerson, R. W., J r. An apparatus for the measurement of thermal diffusivity of foods. Food Technol. 1965, 19, 198204.

Holdsworth, S. D. Optimisation of thermal processing-a review. J . Food Eng. 1985, 4 (2), 89-116.

Holman, J . P. Heat Transfer, 7th ed.; McGraw-Hill: New York, 1990.

Lund, D. B. Design of thermal processes for maximizing nutrient retention. Food Technol. 1977, 31 (2), 71-78.

Lund, D. B. Considerations in modeling food processes. Food Technol. 1983, 37 (1), 92-94.

Norback, J. P. Techniques for optimisation of food processes. Food Technol. 1980, 34 (2), 86-88.

Noronha, J . F. Improved Procedures for Designing, Evaluating and Optimizing In-Pack Thermal Processing of Foods. Ph.D. Thesis, Katholieke Universiteit Leuven, Belgium, 1996.

Silva, C. Optimization of Sterilized Conduction Heating F oods: A Generalized Approach. Ph.D. Dissertation, Universidade Católica Portuguesa, Porto, Portugal, 1993.

Silva, C. L. M.; Oliveira, F. A. R.; Hendrickx, M. Quality optimization of conduction heating foods sterilized in different packages. Int. J . Food Sci. Technol. 1994, 29(5), 515-530.

Silva, F. M. Design and Optimisation of Pasteurization Conditions for Cupuaçu (Theobroma grandiflorum) Fruit Pulp. Ph.D. Thesis, Escola Superior de Biotecnologia, Universidade Católica Portuguesa, Porto, Portugal, 2000.

Silva, F. M.; Silva, C. L. M. Quality optimisation of hot filled pasteurised fruit purées: container characteristics and filling temperatures. J . Food Eng. 1997, 32(4), 351-364.

Silva, F. M.; Silva, C. L. M. Color changes in thermally processed cupuaçu (Theobroma grandiflorum) purée: critical times and kinetics modelling. Int. J . Food Sci. Technol. 1999, 34(1), 8794.

Silva, F. M.; Gibbs, P.; Vieira, M. C.; Silva, C. L. M. Thermal inactivation of Alicyclobacillus acidoterrestris spores under different temperature, soluble solids and $\mathrm{pH}$ conditions for the design of fruit processes. Int. J . Food Microb. 1999, 51(2/ 3), 95-103. 
Silva, F. M.; Sims, C.; Balaban, M. O.; Silva, C. L. M.; O'Keefe, $\mathrm{S}$. Kinetics of flavor and aroma changes in thermally processed cupuaçu (Theobroma grandiflorum) pulp. J . Sci. Food Agric. 2000a, 80(6), 783-787.

Silva, F. M.; Gibbs, P.; Silva, C. L. M. Establishing a new pasteurization criterion based on Alicycl obacillus acidoterrestris spores for shelf-stable high-acidic fruit products. Fruit Process. 2000b, 10(4), 138-141.

Sweat, V. E. Thermal properties of foods. In Engineering Properties of Foods; Rao, M. A., Rizvi, S. S. H., Eds.; Marcel Dekker: New York, 1986.

Teixeira, A. A.; Dixon, J . R.; Zahradnik, J . W.; Zinsmeister, G. E. Computer optimization of nutrient retention in thethermal processing of conduction-heated foods. Food Technol. 1969, 23(6), 137-142.

Van-Boekel, M. A. J . S. Statistical aspects of kinetic modelling for food science problems. J . F ood Sci. 1996, 61(3), 477-485, 489.
Van Loey, A.; Francis, A.; Hendrickx, M.; Maesmans, G.; Noronha, J .; Tobback, P. The optimization of product quality during thermal processing: a case study on white beans in brine. Paper presented at the workshop "Process optimization and minimal processed foods", Porto, Portugal, September 18-24, 1993.

Villota, R.; Hawkes, J . G. Reaction kinetics in food systems. In Handbook of Food Engineering; Heldman, D. R., Lund, D. B., Eds.; Marcel Dekker: New York, 1992; pp 39-144.

Welt, B. A.; Teixeira, A. A.; Chau, K. V.; Balaban, M. O.; Hintenlang, D. E. Explicit finite difference methods for heat transfer and thermal process design. J. Food Sci. 1997, 62 (2), 230-236. 